\title{
COLOR THEORY AND MODELING FOR COMPUTER GRAPHICS, VISUALIZATION, AND MULTIMEDIA APPLICATIONS
}




\section{THE KLUWER INTERNATIONAL SERIES}

IN ENGINEERING AND COMPUTER SCIENCE 


\section{COLOR THEORY AND MODELING FOR COMPUTER GRAPHICS, VISUALIZATION, AND MULTIMEDIA APPLICATIONS}

by

\section{Haim Levkowitz}

University of Massachusetts Lowell

Lowell, Massachusetts, USA

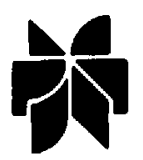

KLUWER ACADEMIC PUBLISHERS

Boston / Dordrecht / London 
Distributors for North America:

Kluwer Academic Publishers

101 Philip Drive

Assinippi Park

Norwell, Massachusetts 02061 USA

Distributors for all other countries:

Kluwer Academic Publishers Group

Distribution Centre

Post Office Box 322

3300 AH Dordrecht, THE NETHERLANDS

\section{Library of Congress Cataloging-in-Publication Data}

A C.I.P. Catalogue record for this book is available from the Library of Congress.

The publisher offers discounts on this book when ordered in bulk quantities. For more information contact: Sales Department, Kluwer Academic Publishers, 101 Philip Drive, Assinippi Park, Norwell, MA 02061

Copyright $\mathbb{C} 1997$ by Kluwer Academic Publishers

All rights reserved. No part of this publication may be reproduced, stored in a retrieval system or transmitted in any form or by any means, mechanical, photocopying, recording, or otherwise, without the prior written permission of the publisher, Kluwer Academic Publishers, 101 Philip Drive, Assinippi Park, Norwell, Massachusetts 02061

Printed on acid-free paper.

Printed in the United States of America 
LIST OF FIGURES Ix ix

LIST OF TABLES xiii

Preface $\quad$ xv

Part I COLOR THEORY 1

1 HUMAN VISION 3

1.1 The Human Interface 3

1.2 Color As a Tri-Stimulus Medium 6

$\begin{array}{ll}1.3 \text { A Tour of the Human Visual System } & 9\end{array}$

$\begin{array}{lll}1.4 & \text { Basic Visual Mechanisms } & 12\end{array}$

1.5 Introduction to Human Color Vision 17

$\begin{array}{ll}1.6 & \text { Color deficiencies } \\ 1.7 & 22\end{array}$

$\begin{array}{lll}1.7 & \text { Color-Luminance Interactions } & 27\end{array}$

$\begin{array}{lll}1.8 & \text { Summary and Notes } & 29\end{array}$

2 COLOR ORGANIZATION AND COLOR MODELS 31

2.1 Introduction to Color Modeling 31

2.2 Overview of Color Specification Systems 33

2.3 Process-dependent Systems (Instrumental) 33

2.4 Process-order Systems (Pseudo-perceptual) 35

2.5 Coordinate Systems Based on Human Visual Models 36

2.6 Perceptually Uniform Systems 40

2.7 Uniform Color Spaces (UCS) 41

2.8 Summary and Notes 44 


\section{COLOR IN COMPUTER GRAPHICS}

3.1 Introduction 46

3.2 The Color Monitor, the Colorcube, and the RGB Model 47

3.3 The Lightness, Hue, and Saturation (LHS) Family of Models 49

3.4 GLHS: A Generalized Lightness, Hue, and Saturation Model $\quad 55$

3.5 Illustrations of GLHS $\quad 69$

$\begin{array}{lll}3.6 & \text { Summary and Notes } & 73\end{array}$

4 MULHS-A MOST UNIFORM LHS MODEL: APPROXIMATING UNIFORM COLOR SPACES WITH THE GLHS FAMILY OF MODELS

4.1 Introduction: A Minimization Problem 76

4.2 GLHS Approximation of the CIELUV Uniform Color Space $\quad 77$

4.3 GLHS Approximation of The Munsell Book of Color $\quad 78$

4.4 Summary and Notes $\quad 80$

5 COLOR VISION FOR COMPLEX VISUAL TASKS

5.1 Color and Visual Search 89

5.2 Visual-Verbal Interactions: The Stroop Effect (1935) 93

5.3 Color Discrimination vs. Color Naming 94

5.4 Color Contrast and Color Constancy 94

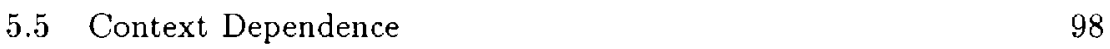

5.6 Temporal Chromatic Effects 98

$\begin{array}{lll}5.7 & \text { Summary and Notes } & 98\end{array}$

Part II APPLICATIONS IN GRAPHICS, VISUALIZATION, AND MUTLIMEDIA APPLICATIONS

6 COLOR DEVICES

6.1 Introduction to Color Calibration 101

$\begin{array}{ll}6.2 \text { Gamut matching } & 106\end{array}$

$\begin{array}{lll}6.3 & \text { Summary and Notes } & 107\end{array}$ 


\section{COLOR SCALES FOR IMAGE DATA:}

\section{DESIGN AND EVALUATION}

7.1 Introduction

7.2 Desired Properties for Color Scales 110

7.3 Commonly Used Scales

7.4 The Problem of Optimal Color Scales

7.5 Solution Approach and Implementation

7.6 Results of OPTIMAL-SCALES

7.7 Linearization of Color Scales

7.8 Evaluation of Optimal Color Scales

7.9 Results of the Evaluation

7.10 Summary and Notes

8 PERCEPTUAL STEPS ALONG COLOR SCALES

8.1 Introduction 135

8.2 Adjusting Perceptual Steps of Color Scales 137

8.3 Linearization of Color Scales 137

8.4 Summary and Notes 142

9 INTEGRATED VISUALIZATION OF MULTIPARAMETER DISTRIBUTIONS 145

9.1 Introduction and Background 145

9.2 Visually-based Integration Techniques: The Iconographic Approach

9.3 Color Integrated Displays Using the GLHS Family of Color Models

9.4 Summary and Notes

10 COLOR ICONS: MERGING COLOR AND TEXTURE PERCEPTION FOR
INTEGRATED VISUALIZATION OF
MULTIPLE PARAMETERS

10.1 Merging Color, Shape, and Texture Perception for Integration: The Original Color Icon

10.2 Illustrations and Examples

10.3 Second Generation: New Design and Implementation 
10.4 Color Icon Surfaces

10.5 Parallel Implementation

10.6 Applications and Examples

10.7 Summary and Notes

11 COLOR ON THE WORLD-WIDE WEB 


\section{LIST OF FIGURES}

\section{Chapter 1}

1.1 Schematic of the eye. 9

1.2 Luminance response function. 13

$\begin{array}{ll}1.3 \text { Contrast sensitivity function. } & 14\end{array}$

$\begin{array}{ll}1.4 & \text { Interlaced vs. non-interlaced flicker. } \\ 1.5 & \text { Individual cone mechanisms are }\end{array}$

1.5 Individual cone mechanisms are color blind. 18

$\begin{array}{ll}1.6 & \text { A bichromatic yellow. } \\ 1.7 & 19\end{array}$

1.7 A monochromatic yellow. 20

1.8 Photoreceptor output recombination into opponent channels. 23

$\begin{array}{ll}1.9 & \text { Abnormal M-type cones. } \\ 1.10 & 24\end{array}$

1.10 Abnormal L-type cones. 25

1.11 Achromatic and chromatic grating detection. 28

1.12 Size and Perceived Color. 30

\section{Chapter 2}

2.1 Continuous variations in hue, saturation, lightness. 32

$\begin{array}{lll}2.2 & \text { Pseudo-perceptual order systems. } & 37\end{array}$

2.3 Pseudo-perceptual order systems. 38

2.4 Pseudo-perceptual order systems. $\quad 39$

\section{Chapter 3}

3.1 The RGB Colorcube. 48

3.2 Tints, shades, and tones. 50

3.3 Points of the same hue as c. 59

3.4 A general cross section through the GLHS Model. 63

3.5 Another general cross section through the GLHS Model. 64

3.6 A third general cross section through the GLHS Model. $\quad 65$

3.7 The RGB-TO-GLHS transformation algorithm. 66 
3.8 The GLHS-TO-RGB transformation algorithm.

3.9 MCMTRANS: Multiple Color Model Specification and Transformation System.

3.10 The plane perpendicular to the main diagonal.

\section{Chapter 4}

4.1 Constant GLHS hue and saturation curves for maximizer space.

4.2 Constant GLHS hue and saturation curves for hexcone.

4.3 GLHS hue plane for maximizer space.

4.4 GLHS hue plane for hexcone.

4.5 Constant Munsell hue and chroma curves in $\left(u^{*}, v^{*}\right)$-coordinates.

4.6 Munsell hue plane in $\left(L^{*}, C_{u v}^{*}\right)$-coordinates.

\section{Chapter 5}

5.1 Preattentive search.

5.2 Preattentive color features distract. (See Web site for color version.)

5.3 Preattentive color features help. (See Web site for color version).

5.4 Visual-verbal interaction, after [Sch90a]. (See Web site for a color version.)

5.5 Perceived color depends on the color of background. 95

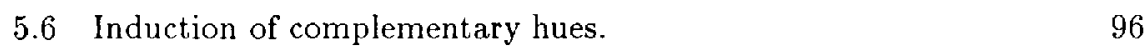

$\begin{array}{lll}5.7 & \text { Color Constancy isn't Perfect (after [WBR87]). } & 97\end{array}$

\section{Chapter 6}

\section{Chapter 7}

7.1 Non-linearized grayscale.

7.2 Linearized grayscale.

7.3 The rainbow scale.

7.4 The heated-object scale.

7.5 The magenta scale.

7.6 Algorithm OPTIMAL-SCALES.

7.7 OCS: The optimal color scale.

7.8 LOCS: The linearized optimal color scale. 
7.9 An example of an abnormal image used in the study.

7.10 ROC curves.

\section{Chapter 8}

8.1 Illustration of the linearization process. 139

8.2 Scale comparison. 143

\section{Chapter 9}

9.1 MCMIDS-Multiple Color Model Image Display System.

\section{Chapter 10}

10.1 The color icon with six linear features.

10.2 A picture of an enlarged color icon.

10.3 Increasing the number of parameters.

10.4 Generation of the three synthesized images.

10.5 The three synthesized images in gray scale.

10.6 The three synthesized images in color models. 160

10.7 The three synthesized images in color icons and LOCS. 161

10.8 The three synthesized images in color icons and separate scales. 162

10.9 The three synthesized images in color icons. 163

10.10MR brain with malignant glioma. $\quad 165$

10.11Brain MR images in color models. $\quad 166$

10.12A color icon integrated image of the two brain sections. Two parameter-to-color-scale mappings are shown. T1 in LOCS,

T2 in heated-object scale.

10.12Another color icon integration of the same section; T1 in heated-object, T2 in LOCS. (See Web site for color versions.)

10.13One-Limb Configuration.

10.14Two-Limb Configuration. $\quad 171$

10.15Three-Limb Configuration. $\quad 172$

10.16Four-Limb Configuration. $\quad 173$

10.17Original images used to implement the iconographic technique

for sensor fusion. (See Web site for color version.) 179

10.18Visible and thermal image integration. $\quad 180$

10.19An integrated image of the FBI homicide database. 181 
10.20Four raw satellite images of the great lakes. (See also a version on the Web site.)

10.21Two color icon integrated images.

10.22Three parameter color icon integration. 185

10.23Four-parameter color icon integration.

\section{Chapter 11}




\section{LIST OF TABLES}

\section{Chapter 1}

1.1 Physical vs. Perceptual Terms.

\section{Chapter 2}

2.1 Color specification systems summary.

2.2 HSL in CIELUV and CIELAB.

\section{Chapter 3}

3.1 Comparison of lightness in LHS models.

3.2 Computer graphics models in GLHS.

Chapter 4

4.1 Average difference values.

\section{Chapter 5}

Chapter 6

\section{Chapter 7}

7.1 The $\Delta(j)$ operators.

7.2 Results of experiments.

\section{Chapter 8}

\section{Chapter 9}

Chapter 10 
10.1 Synthesized data generation.

\section{Chapter 11}


Imagine a world in which the colors you see do not necessarily represent the correct ones. Imagine, when you approach a traffic light, you cannot tell what color the light is. Imagine the colors of traffic lights changing from one block to the next one. Could you?

If you can't, just go to your computer. In the world of visual computing, you cannot be sure what the colors will be. Even today. And today, the awareness of computer professionals to color has grown orders of magnitude.

When I got introduced to some interesting color problems in medical imaging back in 1984 (and thus reintroduced to color, which I had researched and explored in the seventies), it seemed like nobody really bothered; there were very few publications that attempted to understand the relationship between color and the computer.

Within a few years, that number grew significantly. Finally, people were beginning to realize that, just as colors play such an important role in our day-to-day life, they are important on our computer displays. And, thus, color should be studied, and the appropriate usage on computer displays should be explored, understood, and practiced. I cannot say we have reached that stage, yet, but I am glad to report that progress has been made.

This book is the result of over a dozen years of research, teaching, consulting, and advising, first at the Medical Image Processing Group, Department of Radiology, the University of Pennsylvania, and then here at the Institute for Visualization and Perception Research and the Graphics Research Laboratory at the University of Massachusetts Lowell.

I started putting the material presented here together the first time for a halfday color tutorial I taught at the IEEE Visualization ' 91 conference in San Diego. The success of that tutorial suggested that it should be expanded from a half-day to a full-day course, and that inviting other color experts to contribute their expertise would strengthen it. As a result, I invited Philip Robertson (then of CSIRO, Canberra, Australia, and now with Canon Research in Sydney) and Bernice Rogowitz (IBM Research, Yorktown Heights, NY) to join me. We took our "show" to SIGGRAPH '92 in Chicago, and again to IEEE Visualization ' 92 in Boston. Phil's and Bernice's contributions to the tutorial, and thereby to this book, were numerous and significant. I am grateful to them for lending me their vast knowledge and experience. 
Since then I have taught a similar tutorial at several other conferences, and have used parts of this material in my visualization tutorials, as well as in my computer graphics and visualization courses here at Lowell.

Over the years, many people have asked me for advice about their color graphics applications. At some point, I got convinced that many others, who haven't had the opportunity to take the tutorial, and who couldn't ask me questions, could use some of the material presented here. Thus came the idea for of this book.

The goal of this book is not to teach you everything you need to know about color; numerous publications are available to do that. It is not even to teach you everything you need to know about color computer graphics; no, there aren't numerous publication available to do that. The goal of this book is to convince you that it is important to pay attention to color (if you are not convinced yet); to give you the basic fundamentals of color vision in general, and as related to visual computing in particular; to make you aware of the repercussions of your color choices; and to stimulate you to further explore this topics. One not-sohidden agenda: I'd like to encourage students to pick color as their doctoral research topic.

To help us accomplish these goals, we have established a World-Wide Web (http://www.cs.uml.edu/ haim/ColorCenter) site, where you can find all the color images, more information, examples, tools, and links to other related sites. As all good Web sites should be (forever), this site is under construction, and will hopefully remain so. What you will find on the Web site are all the color figures in the book, additional example images, recommended color scales, some useful software tools, an extended, annotated bibliography, and links to other relevant sites.

We would like you to visit the site, and take advantage of what is available there. To make the most of it, we suggest the use of an automatic monitor (such as URL-minder at http://ww . netmind . com/URL-minder/URL-minder.html) to alert you to changes in the site.

We would also appreciate your comments, suggestions, contributions, and critique.

This book would not have materialized if not for many people who have helped me, directly or indirectly, make it happen.

More than fifteen years ago, my colleague and friend Yair Censor influenced to a large degree the direction of my academic career. Gabor Herman, my doctoral 
dissertation advisor, colleague, and friend, made significant contributions to the material presented in this book. Ron Pickett found me at a job I did not enjoy, and together with Georges Grinstein and Stu Smith, brought me over to Umass Lowell, where I have had a wonderful time ever since. Giam Pecelli, our previous Department Chair, and Jim Canning, our current Chair, have both provided me enormous support here; they, together with the rest of the Computer Science Department faculty, have made it so wonderful to work here.

Many extremely capable and dedicated students have worked over the years on projects, the results of which can be found in this book and on the Web site: Kerry Shetline wrote the first versions of MCMTRANS and MCMIDS (and suffered through my notorious bug-finding ability). Nupur Kapoor and Bogdan Pytlik implemented the first version of the color icon. David Gonthier developed the new version of the color icon, and incorporated it in NewExvis, our visualization environment. He was helped by Jude Fatyol, Omar Hoda, and Lisa Masterman. Rob Erbacher developed the parallel implementation of the color icon and the GLHS color model. Krishnan Seetharaman added three-dimensional spaceball navigation to the GLHS color model, and made numerous other contributions, too numerous to list them all. Alex Gee, Pat Hoffman, J.P. Lee, Dave Pinkney, and Marjan Trutschl, have all helped make life at IVPR as pleasant as it is, in many different ways, but mostly in their eagerness to do whatever is necessary, whenever it is necessary. When one is blessed with having so many wonderful students, it is inevitable to forget someone; my apologies to those I have not mentioned: your contributions have been as important and as appreciated.

My family in Israel, Colombia, and here in the US, all deserve my thanks for all they have given me over the years.

Finally, no thanks could be enough to Ea, Merav, and Shir, with whom I should be spending this weekend, instead of in front of my computer, writing this. It's wonderful to have you!

Lowell, Massachusetts

Haim Levkowitz

January 1997 